Jurnal Keperawatan Silampari

Volume 4, Nomor 1, Desember 2020

e-ISSN: 2581-1975

p-ISSN: 2597-7482

DOI: https://doi.org/10.31539/jks.v4i1.1279

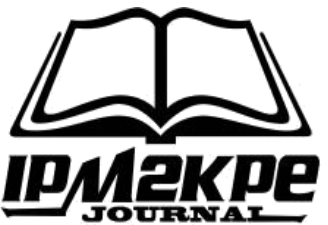

\title{
PERSEPSI KEPALA RUANGAN TENTANG HASIL RECRUITMENT PERAWAT BERBASIS KOMPETENSI
}

\author{
Ernita Rante Rupang ${ }^{1}$, Nurmaini ${ }^{2}$, Roymond H. Simamora ${ }^{3}$ \\ Universitas Sumatera Utara ${ }^{1,2,3}$ \\ ellyrupangfse@gmail.com ${ }^{1}$
}

\begin{abstract}
ABSTRAK
Penelitian ini bertujuan untuk menggali persepsi kepala ruangan tentang hasil recruitment perawat berbasis kompetensi di Rumah Sakit Santa Elisabeth Medan. Metode penelitian yang digunakan adalah penelitiaan kualitatif dengan desain fenomenologi. Hasil penelitian ini memperoleh enam tema utama yaitu: utama 1) tujuan recruitment, 2) perbaikan yang dilakukan dalam recruitment, 3) hambatan implementasi recruitment, 4) manfaat recruitment, 5) faktor pendukung pelaksanaan recruitment, 6) harapan dari hasil recruitment. Simpulan, persepsi kepala ruangan terhadap hasil recruitment perawat berbasis kompetensi dapat membantu tim recruitment yang sekaligus bagian manajemen rumah sakit untuk memperoleh tenaga perawat yang profesional dan kompeten sesuai kebutuhan layanan.
\end{abstract}

Kata Kunci: Kompetensi, Perawat, Recruitment

\section{ABSTRACT}

This study explores the perceptions of the head of the room about the recruitment results of competency-based nurses at Santa Elisabeth Hospital Medan. The research method used is qualitative research with a phenomenological design. The results of this study obtained six main themes, namely: 1) the purpose of recruitment, 2) improvements made in recruitment, 3) obstacles to recruitment implementation, 4) benefits of recruitment, 5) supporting factors for the performance of recruitment, 6) expectations of recruitment results. In conclusion, the head of the room's perception of competency-based nurse recruitment results can help the recruitment team, who is also a part of hospital management, obtain professional and competent nurses according to service needs.

Keywords: Competence, Nurse, Recruitment

\section{PENDAHULUAN}

Pelayanan kesehatan berfokus pada keselamatan pasien sesuai dengan standar pelayanan yang telah ditetapkan untuk memberikan kepuasan bagi pasien yang menerima layanan. Salah satu tuntutan pasien dalam menerima layanan adalah mendapatkan pelayanan yang bermutu dari setiap pemberi layanan di rumah sakit. Komisi Akreditasi Rumah Sakit KARS (2017) telah mereview standar akreditasi yang tertuang dalam Standar Nasional Akreditasi Rumah Sakit dengan maksud agar mutu pelayanan dan keselamatan pasien di Indonesia dapat lebih baik dan tidak kalah dengan rumah sakit di negara lain. Standar pemberi layanan diatur dalam SNARS pada Bab 5 yaitu Kompetensi dan Kewenangan Staf (KKS), dinyatakan bahwa pimpinan menetapkan persyaratan 
pendidikan, kompetensi, kewenangan, keterampilan, pengetahuan, dan pengalaman staf untuk memenuhi kebutuhan memberikan asuhan kepada pasien.

Hasil penelitian Singh (2020) menyatakan bahwa perawat adalah tulang punggung kesehatan maka semua negara diharapkan untuk berinvestasi terhadap perawat sebagai bagian dari komitmen terhadap kesehatan. Glasper (2020) menyatakan bahwa perawat adalah aset yang paling berharga yang dimiliki oleh national health service (NHS) dan merupakan investasi bagi pemerintah maka perlu dipertimbangkan untuk pengembangan pendidikan berkelanjutan yang tercantum dalam pedoman kepegawaian pelayanan pasien di ruang rawat inap. Tenaga keperawatan memberikan layanan asuhan keperawatan, sehingga profesi perawat memiliki andil untuk mewujudkan kualitas pelayanan setiap saat secara profesional.

Carpentier et al., (2017) menyatakan bahwa untuk mendapatkan tenaga perawat sesuai dengan kebutuhan, kompetensi yang dibutuhkan maka dilakukan proses recruitment melalui media sosial. Menurut Renteria (2020) menyatakan bahwa untuk mengisi posisi yang kosong dalam pelayaan keperawatan sesuai dengan kualifikasi yang dibutuhkan merupakan bagian utama dari kegiatan recruitment. Hasil penelitian Coustas (2019) di Afrika Selatan menyatakan bahwa kelompok rumah sakit besar di Afrika Selatan merekrut perawat yang beketerampilan tinggi dan berdedikasi untuk meningkatkan pelayanan sesuai dengan tuntutan pelayanan.

Tujuan diadakannya recruitment adalah menciptakan kumpulan sumber daya manusia yang memenuhi syarat untuk organisasi dengan menarik lebih banyak karyawan untuk ditetapkan dalam organisasi. Proses seleksi yang merupakan bagian dari recruitment bertujuan memilih sumber daya manusia yang tepat untuk mengisi berbagai posisi yang dibutuhkan dala organisasi (Aulia, 2019). Hasil penelitian Mbugua \& Kamaara (2017) Menyatakan bahwa semakin objektif perekrutan dan kriteria pemilihan SDM, maka kinerja akan semakin baik. Gunawan et al., (2019) menyatakan bahwa kompetensi digunakan untuk membandingkan dan membedakan kapasitas perawat, maka proses recruitment akan mudah jika perawat menunjukkan pengetahuan, keterampilan dan sikap.

Komitmen untuk perekrutan perawat dengan berfokus pada peran perawat dapat mengakibatkan penurunan turn over, kerjasama dengan istansi pendidikan dan instansi lain dapat meningkatkan efektifitas recruitment sehingga sumber daya manunsia yang direkrut mengisi lowongan sesuai dengan kebutuhan pelaanan (Gion \& Abitz, 2019).

Penerimaan SDM dengan prioritas lulusan STIKes Santa Elisabeth menghasilkan perawat yang diterima lebih banyak yang baru tamat, belum berpengalaman, kurang kompeten dan juga kurang memiliki keunggulan kompetitif dibandingkan dengan pelayanan di rumah sakit yang lain. Meningkatnya turnover perawat khususnya yang masih menjalani tahap orientasi menjadi permasalahan di Rumah Sakit Santa Elisabeth Medan. Tingginya jumlah sumber daya manusia (SDM) yang keluar pada bulan pertama menunjukkan adanya kesalahan pada pihak yang menerima. Kesalahan tersebut bisa terjadi karena SDM yang diterima tidak mencirikan atau menggambarkan kebutuhan ruangan. Kajian kebutuhan ruangan dengan SDM yang akan di supply ke ruangan yang membutuhkan merupakan kegiatan recruitment. Maka menjadi perhatian bagi pihak manajemen rumah sakit agar memberikan perhatian khusus pada pentingnya perencanaan dan proses pelaksanaan recruitment perawat.

Recruitment perawat yang dilaksanakan di tempat penelitian menggunakan panduan recruitment yang tersedia. Peneliti sebelumnya telah melakukan penelitan mengenai hasil recruitment, namun penelitian ini memfokuskan pada persepsi kepala ruangan tentang 
hasil recruitment perawat berbasis kompetensi yang belum pernah dilakukan di tempat penelitian.

\section{METODE PENELITIAN}

Metode penelitian menggunakan pendekatan kualitatif fenomenologi untuk mengeksplorasi persepsi kepala ruangan dan tim recruitment yang merupakan bagian manajemen rumah sakit. Partisipan dalam penelitian adalah tim recruitment perawat Rumah Sakit Santa Elisabeth Medan yang terdiri dari wakil direktur pelayanan keperawatan, ketua komite keperawatan, kepala bagian perawatan umum, kepala bagian perawatan intensif, kepala bagian HRD, kepala bagian perencanaan dan pengembangan sumber daya manusia dan kepala ruangan. Jumlah partisipan dalam penelitian ini adalah 16 orang yang terdiri dari 10 orang kepala ruangan yang terlibat kegiatan Focus group discussion (FGD) dan 6 orang tim recruitment pada in depth interviews.

Pengumpulan data melalui metode focus group discussion (FGD) dan in depth interview dalam waktu kurang lebih 60 menit. Pada saat melakukan focus group discussion (FGD) dan in depth interview peneliti menggunakan panduan focus group discussion (FGD) dan in depth interview sebagai alat bantu dalam mengajukan pertanyaan kepada partisipan. Data yang diperoleh dari FGD dan In depth interviews dimasukkan ke dalam bentuk transcript kemudian dianalisa dengan menggunakan teknik content analysis.

\section{HASIL PENELITIAN}

Tabel. 1

Karakteristik Demografi Partisipan

(Tim Recruitment dan Kepala Ruangan)

\begin{tabular}{clcc}
\hline No & \multicolumn{1}{c}{ Karakteristik } & Frekuensi (f) & Persentase (\%) \\
\hline 1 & Usia & 2 & \\
& 25-30 tahun & 2 & $12,5 \%$ \\
& 31-35 tahun & 5 & $12,5 \%$ \\
& 36-40 tahun & 7 & $31,25 \%$ \\
& $>40$ tahun keatas & & $43,75 \%$ \\
\hline 2 & Jenis Kelamin & 4 & \\
& Laki-laki & 12 & $25 \%$ \\
& Perempuan & & $75 \%$ \\
\hline 3 & Pendidikan Terakhir & 1 & \\
& S2 & 15 & $6,25 \%$ \\
& Ners & & $93,75 \%$ \\
\hline 4 & Jabatan & 1 & \\
& Wakil Direktur Pelayanan Keperawatan & 1 & $6,25 \%$ \\
& Ketua Komite Keperawatan & 2 & $6,25 \%$ \\
& Kepala Bagian Rawat Inap & 1 & $12,25 \%$ \\
& Kepala Unit PPSDM & 1 & $6,25 \%$ \\
& Kepala Bagian SDM & $6,25 \%$ \\
& Kepala Ruangan & 10 & $62,5 \%$ \\
\hline
\end{tabular}


Berdasarkan tabel 1 diketahui bahwa partisipan lebih banyak pada kelompok usia > 40 tahun keatas $(43,75 \%)$, jenis kelamin partisipan mayoritas perempuan yaitu 12 orang $(75 \%)$, latar belakang pendidikan mayoritas ners yaitu 15 orang $(93,7 \%)$ sedangkan jabatan sebagian besar kepala ruangan yaitu 10 orang $(62,5 \%)$.

Kegiatan $F G D$ dan in depth interviews yang dilakukan secara langsung dengan partisipan, menghasilkan 6 tema yaitu 1) tujuan recruitment, 2) perbaikan yang dilakukan dalam recruitment, 3) hambatan yang dialami dalam implementasi recruitment, 4) manfaat dari recruitment, 5) faktor pendukung dalam pelaksanaan recruitment, 6) harapan hasil recruitment perawat berbasis kompetensi.

\section{Tema 1 Tujuan Recruitment Perawat Berbasis Kompetensi}

Partisipan menyatakan bahwa tujuan recruitment perawat berbasis kompetensi membantu tim recruitment untuk memperoleh perawat yang profesional dan kompeten sesuai dengan kebutuhan layanan. Hal tersebut dinyatakan oleh partisipan dalam ungkapan berikut ini:

",,tapi dengan adanya metode rekrutmen ini memang sangat bagus, jadi kita memang tidak terlalu banyak mendapat perawat yang bisa lulus ujian seleksi tapi hasilnya memang berbobotlah dibandingkan selama bertahun-tahun asal diterima aja” P2

“...soalnya memang agak sulit ya, tapi karena sudah dibedakan tipenya perawat D3 dengan ners, ya, jadi lebih bagus memang, jelas dia kompetensinya, ujian praktek juga begitu, baguslah memang jadi sangat menolong ruangan tidak capek kita mengajari, ya,,, sudah lebih pintar gitu” P7

",,janganlah diganti lagi nanti cara ini kalau berganti pejabat, kita kan kadang seperti itu, ganti pejabat, ya ganti semua cara padahal kan sudah bagus sekali ini, apalgi untuk kami di ruangan sangat membantu sekali"(P1)

\section{Tema 2 Perbaikan yang Dilakukan dalam Recruitment Perawat}

Partisipan menyatakan bahwa perbaikan yang dilakukan adalah prosedur recruitment dilaksanakan sesuai dengan regulasi, pedoman, standar prosedur operasional yang telah terbentuk dengan alur yang jelas dan melibatkan seluruh tim recruitment dari bagian keperawatan. Dinyatakan oleh partisipan dengan ungkapan sebagai berikut:

"....boleh tetapi harus ada limit waktunya misalnya untuk narkoba 1 bulan terakhir, untuk hasil darah dari laboratorium klinik yang terakreditasi misalnya Prodia" (P1)

"...tapi benarlah wawancara ini tahap akhir karena disitulah semua disampaikan" $(P 2)$

"bagus sekali cara prosedur ini, orang luar kan tau juga kapan kita menerima perawat, jadi tidak asal-asal terima, kita menunggu pula mereka datang, padahal yang tidak kompeten sedikitpun tapi ya itulah ya karna dari sekolah kita kita terimalah semua. Jadi kita benarlah menggunakan pedoman yang sudah ada ini..."

\section{Tema 3 Hambatan yang Dialami dalam Tahap Recruitment}

Hambatan yang ditemukan dalam setiap tahap sesuai alur recruitment: jumlah pelamar tidak mencapai jumlah perawat yang dibutuhkan, hasil uji tulis belum tercapai sesuai standar, fasilitas untuk uji skill tidak lengkap jika dilakukan di lab skill, biaya tes kesehatan mahal. Hal tersebut dinyatakan oleh partisipan dengan ungkapan:

“....standar kitapun adanya 70 Cuma 60 pun tidak tercapai maka diturunkanlah standarnya." (P7) 
"praktek harus lebih tinggi, cuma bagaimana seperti ketika harusnya kan uji skill tidak langsung ke pasien.” (P3)

"sebenarnya kan masih belum cukup perawat yang kita terima ini karena ya ada standar tidak lullus mereka padahal lulusan kita itu yang tidak lulus, bagaimanalah cara kita supaya lebih banyak lagi yang lulus ya,,, tapi jangan diturunkan sandar kelulusannyalah" (P6)

",,,bisalah buk direktur, diturunkanlah sedikit harga tes kesehatan itu memang terlalu mahal itu, diulang-ulang lagi narkoba,,,cukuplah 1 kali ah kan yang penting masih berlaku" (P9)

\section{Tema 4 Manfaat dari Recruitment Perawat Berbasis Kompetensi}

Manfaat dari recruitment perawat berbasis kompetensi yang dilaksanakan sesuai kebijakan, pedoman, dan standar prosedur operasional mendapatkan hasil lebih optimal dibandingkan hasil recruitment menggunakan kebijakan yang lama. Manfaat tersebut dinyatakan partisipan dengan ungkapan berikut:

“...ada manfaatnya, artinya ada perbedaan, kita kerja juga enak, gak nanya lagi habis itu kemana, kalau ini kan sudah jelas." (P1)

"sebenarnya kalau sudah ada ini juga sudah tidak terlalu kuatir lagi kekurangan tenaga, asal sesuai upah jugalah buk direktur ya." (P2)

\section{Tema 5 Faktor Pendukung dalam Pelaksanaan Recruitment}

Faktor pendukung dalam pelaksanaan recruitment: kerjasama antar pihak manajemen dan semua yang terlibat dalam proses recruitment perawat, komitmen dalam melaksanakan regulasi, pedoman, SPO, keterbukaan pihak manajemen rumah sakit menerima masukan dari luar. Dinyatakan oleh partisipan dengan ungkapan sebagai berikut:

“... sebenarnya bisa gak ada nilai dari hasil wawancara kita kuantifikasikan gitu, bisa di nilai disiplin dan yang lain-lain, bagaimanalah kita menilai itu, bisalah dibantu dari pembimbing ya, tim seleksi punya komitmen untuk melaksanakan ini, kerjasama antar tim." (PI)

“...mulai dari persiapan ketua tim seleksi sudah memberitahukan ke anggota apa yang akan dilakukan.” (P7)

“... bagus sekali memang karena kami yang memakai ini dilibatkan pihak manajemen, jadi ada jugalah kesempatan kami untuk bicara, ya menilai yang mau diterima gitu” (P12)

\section{Tema 6 Harapan dari Hasil Recruitment Perawat Berbasis Kompetensi}

Harapan dari hasil recruitment perawat adalah: proses recruitment sesuai standar dan lebih bermutu, hasil recruitment lebih optimal, untuk peneliti berikutnya tetap melibatkan pihak manajemen tidak hanya penelitian di lapangan. Harapan tersebut dinyatakan oleh partisipan dengan ungkapan:

"...harapan ya dengan adanya begini proses terstandar, hasilnya juga akan lebih baik.” (P1)

“....harapannya ya, pihak manajemen juga ya tidak memberikan harapan yang tidak jelas, penerimaannya bagus sampai didalam yah,,, maka marilah kita berusaha memperbaiki. Harapannya sih kalau ada peneliti melibatkan manajemen tidak hanya langsung lapangan, seperti ini langsung melibatkan manajemen." (P2) 


\section{PEMBAHASAN}

Penelitian Silviana \& Darmawan (2019) menyatakan bahwa kompetensi tenaga kesehatan adalah faktor sangat penting untuk meningkatkan layanan kesehatan. Hasil dari penelitian ini menunjukkan gambaran persepsi kepala ruangan dan tim recruitment perawat tentang pelaksanaan kegiatan recruitment perawat berbasis kompetensi. Tema pertama menunjukkan tujuan dari diadakannya recruitment perawat yaitu untuk memperoleh perawat yang profesional dan kompeten sesuai dengan kebutuhan layanan. Tujuan diadakannya recruitment menurut hasil penelitian Renteria (2020) adalah perekrutan yang dilakukan dengan mengutamakan kualifikasi dilakukan untuk mengisi posisi yang kosong dalam layanan keperawatan. Salah satu alasan merekrut SDM di rumah sakit adalah kekurangan tenaga perawat yang disebabkan oleh turn over yang setiap tahun meningkat oleh karena itu perekrutan dilakukan berdasarkan jumlah kekurangan SDM (Permatasari, 2019). Hasil penelitian Ashwood et al., (2018) menyatakan bahwa tujuan utama recruitment adalah mencari tenaga perawat sesuai dengan kualifikasi untuk pelayanan yang profesional demi pencapaian kepuasan penerima layanan.

Muslim \& Sutinah (2020) menyatakan bahwa perawat merupakan SDM terbesar yang memiliki peran penting dalam menjaga dan meningkatkan pelayanan kesehatan di rumah sakit, perawat bertanggungjawab dalam memberikan pelayanan keperawatan kepada pasien sesuai kompetensi dan kewenangannya. Dengan bertambahnya kemampuan dan kompetensi akan dapat dijadikan dasar untuk penentuan karier perawat. Standar kompetensi mencakup pengetahuan, keterampilan dan sikap tertentu dari suatu profesi dalam ciri keahlian tertentu yang menjadi ciri dari seorang profesional. Jika perawat dapat menunjukkan pengetahuan, sikap dan keterampilan yang baik dalam bekerja maka perawat akan mudah dalam melakukan asuhan keperawatan (Indriani, 2018). Hisgen et al., (2018) menyatakan bahwa mendesain ulang proses recruitment mendukung efisiensi operasional organisasi terkait recruitment perawat.

Tema kedua yang dihasilkan dari penelitian ini yaitu perbaikan yang dilakukan dalam recruitment perawat adalah komitmen pihak manajemen untuk melaksanakan kegiatan recruitment sesuai dengan regulasi yang telah ditetapkan. Standar prosedur untuk praktik perlu ditinjau untuk memastikan bahwa pelayanan dilakukan secara konsisten sesuai dengan pedoman (Ost et al., 2020). Perekrutan yang dilakukan dengan objektif akan memiliki pengaruh kinerja SDM karena memungkinkan institusi untuk merekrut SDM yang terbaik maka recruitment dan seleksi SDM harus dilakukan berdasarkan prestasi dengan melibatkan recruitment internal dan eksternal, sebaliknya perencanaan kebutuhan recruitment yang tidak efektif mengakibatkan kekurangan SDM dalam pemberian pelayanan (Marć et al., 2019).

Kordes et al., (2020) menyatakan bahwa recruitment perawat akan semakin ketat karena menuntut standar dalam praktik sehingga recruitment dilakukan tidak berdasarkan nirlaba tetapi kualifikasi sesuai standar pelayanan. Recruitment yang dilaksanakan sesuai dengan kualifikasi layanan akan tercapai jika didukung oleh pihak manajemen/manajer melalui kepedulian terhadap staff terutama memperhatikan keseimbangan antara kerja dengan upah yang diterima (Steele-Moses, 2018). Kesuksesan recruitment ditentukan oleh persiapan, perencanaan secara fleksibel yang mencakup kebutuhan untuk mengisi kekosongan posisi dalam pelayanan dan untuk mengantisipasi kemungkinan kekurangan tenaga (Johnson et al., 2018). 
Beberapa hambatan yang ditemukan dalam proses recruitment yaitu: jumlah perawat yang melamar dan diterima tidak memenuhi jumlah kebutuhan layanan dan meningkatnya turn over perawat sebelum masa orientasi. Penelitian Kumaladewi (2018) menyatakan bahwa terbatasnya sumber daya manusia dalam proses rekrutmen, dikarenakan tidak ada tenaga khusus untuk membantu penerapan evaluasi manfaat rekrutmen dalam hubungannya dengan media sosial. Beech et al., (2019) menunjukkan bahwa tingkat kekosongan perawat di nurse health service sangat tinggi diakibatkan oleh turn over. Hambatan dalam pelaksanaan recruitment adalah keuangan yang tidak memadai, kurangnya dukungan dari masing-masing pengambil keputusan (Johnson et al., 2018). Penelitian Molokomme et al., (2018) di Afrika Selatan menunjukkan bahwa kesalahan pengelolaan dana dan pengeluaran secara tidak teratur serta komunikasi yang tidak efektif dengan semua pemangku kepentingan yang terlibat dalam implementasi national health insurance. Hal ini menimbulkan sebuah kesenjangan bagi petugas kesehatan. Kemungkinan faktor iklim organisasi menjadi penghambat perawat untuk memanfaatkan sepenuhnya kompetensi, profesionalisme sesuai dengan ruang lingkup praktik keperawatan (Alenius, 2019).

Manfaat dari recruitment perawat berbasis kompetensi adalah dengan melaksanakan prosedur yang benar membantu tim recruitment, manajemen rumah sakit untuk memperoleh perawat yang profesional dan kompeten sesuai dengan kebutuhan layanan. Hovland et al., (2018) menyatakan bahwa kompetensi menjadi fokus untuk pelayanan perawat di masa depan karena kompetensi dapat digunakan untuk menilai pelayanan perawat baik pengetahuan, skill dan praktik.

Faktor pendukung pelaksanaan recruitment yaitu: kerjasama antar pihak manajemen dan semua yang terlibat dalam proses recruitment perawat, komitmen dalam melaksanakan regulasi, pedoman, SPO, keterbukaan pihak manajemen rumah sakit menerima masukan dari luar. Harapan dari hasil recruitment perawat adalah adanya komitmen dari pihak manajemen dan tim recruitment untuk melaksanakan kegiatan sesuai dengan regulasi yang telah ditetapkan sehingga hasil kegiatan recruitment lebih sesuai dengan kebutuhan pelayanan.

\section{SIMPULAN}

Hasil penelitian ini menghasilkan 6 tema mengenai persepsi kepala ruangan tentang hasil recruitment perawat berbasis kompetensi di rumah Sakit santa Elisabeth Medan yaitu: tujuan recruitment, 2) perbaikan yang dilakukan dalam recruitment, 3) hambatan implementasi recruitment, 4) manfaat recruitment, 5) faktor pendukung pelaksanaan recruitment, 6) harapan dari hasil recruitment. Persepsi kepala ruangan dan tim recruitment terhadap hasil kegiatan recruitment perawat membantu untuk memperoleh tenaga perawat yang profesional dan kompeten walaupun dari segi jumlah yang diterima belum optimal sesuai kebutuhan pelayanan.

\section{SARAN}

Pihak manajemen rumah sakit memiliki komitmen untuk melaksanakan kegiatan recruitment sesuai dengan regulasi, pedoman recruitment yang telah diberlakukan. Peneliti juga merekomendasikan kepada peneliti selanjutnya untuk melakukan evaluasi terhadap hasil recruitment yang memberikan pelayanan di ruang rawat inap. 


\section{DAFTAR PUSTAKA}

Alenius, L. S. (2019). Conditions for Care-Factors in the Nurse Work Environment Related to Safe and High Quality Care in Acute Care Hospitals. Socialmedicinsk Tidskrift, 96(1), 135-136. https://openarchive.ki.se/xmlui/handle/10616/46534

Ashwood, L., Macrae, A., \& Marsden, P. (2018). Recruitment And Retention In General Practice Nursing: What About Pay? Practice Nursing, 29(2), 83-87. https://doi.org/10.12968/pnur.2018.29.2.83

Aulia, A. F. (2019). Analisis Pelaksanaan Rekrutmen dan Seleksi Calon Karyawan Baru di RSIA Kendangsari MERR Surabaya. Medical Technology and Public Health Journal, 3(2), 107-119. DOI: 10.33086/mtphj.v3i2.690

Beech, J., Bottery, S., Charlesworth, A., Evans, H., Gershlick, B., Hemmings, N., Imison, C., Kahtan, P., McKenna, H., \& Murray, R. (2019). Closing The Gap: Key Areas For Action On The Health And Care Workforce. London, UK: Kings Fund. https://www.kingsfund.org.uk/publications/closing-gap-health-care-workforce

Carpentier, M., Van, H. G., Stockman, S., Schollaert, E., Van Theemsche, B., \& Jacobs, G. (2017). Recruiting Nurses Through Social Media: Effects On Employer Brand And Attractiveness. Journal of Advanced Nursing, 73(11), 2696-2708. DOI: 10.1111/jan. 13336

Coustas, E. L. (2019). Factors Impacting the Retention of Registered Nurses Recruited From India to Work in South African Hospitals: A Case Study. International Journal of Africa Nursing Sciences, 10, 6-13. DOI: 10.1016/j.ijans.2018.11.003

Gion, T., \& Abitz, T. (2019). An Approach to Recruitment and Retention of Certified Nursing Assistants Using Innovation and Collaboration. Journal of Nursing Administration, $\quad$ 49(7-8), https://doi.org/10.1097/NNA.0000000000000767

354-358.

Glasper, A. (2020). Strategies to Enhance Nursing Recruitment. British Journal of Healthcare Assistants, 14(2), 70-73. DOI: 10.12968/bjha.2020.14.2.70

Gunawan, J., Aungsuroch, Y., \& Fisher, M. L. (2019). Competence-Based Human Resource Management in Nursing: A Literature Review. Nursing Forum, 54(1), 91-101. https://doi.org/10.1111/nuf.12302

Hisgen, S. A., Page, N. E., Thornlow, D. K., \& Merwin, E. I. (2018). Reducing RN Vacancy Rate: A Nursing Recruitment Office Process Improvement Project. Jona: The Journal of Nursing Administration, 48(6), 316-322. DOI: 10.1097/NNA.0000000000000621

Hovland, G., Kyrkjebø, D., Andersen, J. R., \& Råholm, M. B. (2018). Self-Assessed Competence among Nurses Working in Municipal Health-Care Services in Norway. British Journal of Community Nursing, 23(4), 162-169. DOI: 10.12968/bjen.2018.23.4.162

Indriani, I. (2018). Pengaruh Kompetensi dan Beban Kerja terhadap Kinerja Pelaksanaan Asuhan Keperawatan pada Bagian Rawat Inap Rumah Sakit Umum Dr Slamet Garut. Jurnal Wacana Ekonomi, 17(2), 25-32. https://journal.uniga.ac.id/index.php/JA/article/view/332

Johnson, A. M., Jones, S. B., Duncan, P. W., Bushnell, C. D., Coleman, S. W., Mettam, L. H., Kucharska-Newton, A. M., Sissine, M. E., \& Rosamond, W. D. (2018). Hospital Recruitment for a Pragmatic Cluster-Randomized Clinical Trial: Lessons Learned from the Compass Study. Trials, 19(1), 1-9. DOI: 10.1186/s13063-017-2434-1

KARS, K. A. R. (2017). Standar Nasional Akreditasi Rumah Sakit Edisi 1. Jakarta: KARS 
Kordes, J., Pütz, R., \& Rand, S. (2020). Analyzing Migration Management: On the Recruitment of Nurses to Germany. Social Sciences, 9(2), 19. DOI: 10.3390/socsci9020019

Kumaladewi, A. (2018). Efektifitas Rekrutmen dan Seleksi dalam Memenuhi Kebutuhan Tenaga Perawat di RSIA Muslimat Jombang. Parsimonia-Jurnal Ekonomi Dan Bisnis, $5(1)$, 29-40. https://jurnal.machung.ac.id/index.php/parsimonia/article/view/165

Marć, M., Bartosiewicz, A., Burzyńska, J., Chmiel, Z., \& Januszewicz, P. (2019). A Nursing Shortage-A Prospect of Global and Local Policies. International Nursing Review, 66(1), 9-16. DOI: 10.1111/inr.12473

Mbugua, R. W. K., \& Kamaara, M. (2017). Influence of Recruitment and Selection Criteria on EMmployee Retention in the Insurance Industry in Kenya. Journal of Human Resource and Leadership, 2(7), 17-40. DOI: 10.47604/jhrl.484

Molokomme, V. K., Seekoe, E., \& Goon, D. T. (2018). The Perception of Professional Nurses About the Introduction of the National Health Insurance (NHI) in A Private Hospital in Gauteng, South Africa. The Open Public Health Journal, 11(1), 234242. DOI: $10.2174 / 1874944501811010234$

Muslim, A., \& Sutinah, S. (2020). Pengembangan Karier Profesional Perawat Non PNS di Rumah Sakit X. Jurnal Manajemen Kesehatan Yayasan RS. Dr. Soetomo, 6(1), 16-27. DOI: 10.29241/jmk.v6i1.262

Ost, K., Blalock, C., Fagan, M., Sweeney, K. M., \& Miller-Hoover, S. R. (2020). Aligning Organizational Culture And Infrastructure to Support Evidence-Based Practice. Critical Care Nurse, 40(3), 59-63. DOI: 10.4037/ccn2020963

Permatasari, A. D. S. (2019). Pengaruh Pemasaran Internal terhadap Kepuasan Kerja Perawat di Ruang Rawat Inap Rumah Sakit Islam Faisal di Kota Makassar. Jurnal Mitrasehat, 9(2), 650-663. https://journal.stikmakassar.com/a/article/view/53

Renteria, A. (2020). Recruiting and Retaining NP Preceptors. DNP_QUALIFYING, 88. https://repository.usfca.edu/dnp_qualifying/28

Silviana, S., \& Darmawan, E. S. (2019). Analisis Standar Kompetensi Tenaga Kesehatan di Rumah Sakit Bhakti Yudha Depok Tahun 2017. Jurnal Administrasi Rumah Sakit Indonesia, 4(1), 35-47. DOI: http://dx.doi.org/10.7454/arsi.v4i1.3204

Singh, S. (2020). Nursing Humanities, Nurturing Compassion: Sustaining the Global Nursing and Midwifery Agenda. Research \& Humanities in Medical Education, 7, 1-3. https://www.rhime.in/ojs/index.php/rhime/article/view/253/271

Steele-Moses, S. (2018). Recruitment Attributes Important to New Nurse Graduates Employed on Adult Medical-Surgical Units. Medsurg Nursing, 27(5), 310-328. http://ovidsp.ovid.com/ovidweb.cgi?T=JS\&PAGE=reference $\& D=0$ ovtt $\& N E W S=N$ \&AN=00008484-201809000-00009 